\title{
ALEITAMENTO MATERNO: UMA ABORDAGEM SOBRE O PAPEL DO ENFERMEIRO NO PÓS-PARTO
}

BREAST-FEEDING: AN APPROACH ABOUT NURSE PERFORMANCE IN IMMEDIATE POST-BIRTH

LACTANCIA MATERNA: UN ABORDAJE DEL PAPEL DE LA ENFERMERA EN DESPUÉS DEL PARTO

Nilza Alves Marques Almeida ${ }^{1}$
Aline Garcia Fernandes ${ }^{2}$
Cleide Gomes de Araújo $^{3}$

RESUMO: Este estudo, de caráter descritivo, objetivou identificar a atuação do enfermeiro na promoção, incentivo e apoio ao aleitamento materno no pós-parto imediato. Realizou-se entrevista individual com 21 enfermeiras de três maternidades públicas de Goiânia-GO, Brasil. Os resultados revelaram que: 1) Todas as enfermeiras têm atuação e conhecimento específico em aleitamento materno; 2) Duas das maternidades possuem equipe multiprofissional de promoção, incentivo e apoio ao aleitamento materno, com participação do enfermeiro, e receberam o título de "Hospital Amigo da Criança"; 3) Somente uma maternidade apresenta estrutura física adequada, banco de leite humano e quantitativo de enfermeiros suficiente para a atuação eficaz e direcionada ao aleitamento materno; 4) Em uma das maternidades, o fonaudiólogo tem maior atuação em aleitamento materno do que o enfermeiro; 5) Em nenhuma das maternidades é realizada a sistematização da assistência de enfermagem. Concluiu-se que a atuação do enfermeiro na promoção, no incentivo e apoio ao aleitamento materno foi mais expressiva e efetiva na maternidade que apresenta filosofia, estrutura física e equipe multiprofissional de referência no parto humanizado. Esta maternidade recebeu os títulos de "Hospital Amigo da Criança" e "Maternidade Segura".

PALAVRAS-CHAVES: Enfermagem Materno-Infantil; Aleitamento Materno; Puerpério.

ABSTRACT: This is a descriptive study that has the aim of identifying the job of the nurse, referring to the promotion, incentive and support to the mother breast-feeding at the immediate post-birth. It was realized an interview with twenty one nurses in three different public maternity wards in Goiânia-GO, Brazil. The results revealed that: 1) All the nurses have specific knowledge about mother breast-feeding; 2)Two of the maternities have a multiprofessional team for the promotion, incentive and support mother breast-feeding, and they were entitled Child Friend Hospital; 3) Only one maternity ward presents an appropriate physical structure, human milk support and nurses sufficient for an efficient and directed performance to the mother breast-feeding; 4) In one of the maternity wards, the speech pathologist has a better performance than the nurse in the mother breast feeding; 5 ) it was realized that there was no nurse work systematization in any of the maternity wards. We concluded that the nurse performance at the promotion, the incentive and support to the mother breast-feeding was more expressive and efficient at the maternity that presents philosophy, physical structure and a multiprofessional team as reference in the human birth. This maternity ward was called Child Friend Hospital and Safe Maternity Ward.

KEYWORDS: Maternal-child Nursing; Breast Feeding; Puerperium.

RESUMEN: Este estudio, de carácter descriptivo, objetivo identificar la actuación del enfermera en la promoción, incentivo y apoyo al lactancia materna en después del parto. Se Realizó entrevista individual con 21 enfermeras de tres maternidades públicas de Goiânia-GO, Brasil. Los resultados revelaron que: 1)Todas las enfermeras tienen actuación y conocimiento específico em el lactancia materna; 2)Dos de las maternidades poseen equipo multiprofisional de promoción, incentivo y apoyo al lactancia materna con participación del enfermero y hubieron recibido el título de Hospital "Amigo de los Niños"; 3) Solamente una maternidad presenta estructura física adecuada, banco de leche humana y cuantitativo de enfermeros suficiente para la actuación eficaz y direccionada al lactancia materna; 4) En una de las maternidades, el profesional de la lengua y de la audiencia tiene mayor actuación en la lactancia materna que el enfermero; 5) En ninguna de las maternidades es realizada la sistematización de la asistencia de enfermería. Se Concluyó que la actuación del enfermero en fue más expresiva y efectiva en la maternidad que presenta filosofía, estructura física y equipo multiprofisonal de referencia en el parto humanizado. Esta maternidad recibió los títulos de Hospital "Amigo de los Niños " y Maternidad "Segura".

PALABRAS-CLAVES: Enfermería Maternoinfantil; Lactancia Materna; Puerperio.

\footnotetext{
Enfermeira. Mestre em Biologia. Professora Assistente da Faculdade de Enfermagem da Universidade Federal de Goiás. E-mail: nilza@fen.ufg.br. Endereço: rua 227-A, n.0 72, apto. 804, Residencial Arapoema, Setor Universitário, CEP:74610155.

${ }^{2}$ Enfermeira. Unidade Básica de Saúde da Secretaria Municipal de Anápolis, estado de Goiás. e-mail: alinegf@yahoo.com.br

${ }^{3}$ Enfermeira. Unidade Básica de Saúde da Secretaria Municipal de Anápolis, estado de Goiás. e-mail: cleidegomesdearaujo@yahoo.com.br.
} 


\section{INTRODUÇÃO}

O aleitamento materno é sinônimo de sobrevivência para o recém-nascido, portanto um direito inato (ICHISATO \& SHIMO, 2002). É uma das maneiras mais eficientes de atender os aspectos nutricionais, imunológicos e psicológicos da criança em seu primeiro ano de vida (ICHISATO \& SHIMO, 2001).

É uma prática natural e eficaz. Um ato cujo sucesso depende de fatores históricos, sociais, culturais, epsicológicos da puérpera e do compromisso e conhecimento técnico-científico dos profissionais de saúde envolvidos na promoção, incentivo e apoio ao aleitamento materno.

O profissional de saúde deve identificar durante o pré-natal os conhecimentos, a experiência prática, as crenças e a vivência social e familiar da gestante a fim de promover educação em saúde para o aleitamento materno, assim como, garantir vigilância e efetividade durante a assistência a nutriz no pós-parto.

$\mathrm{O}$ aleitamento materno deve ser exclusivo até o sexto mês de vida, e mantido associado a outros alimentos até o segundo ano de vida conforme preconizado pelo Ministério da Saúde (MS), Organização Mundial de Saúde (OMS), Fundo das Nações Unidas para a Infância (UNICEF) e a World Health Organization (VENÂNCIO, 2003).

O real impacto social do aleitamento materno pode ser quantificado através da diminuição de atendimento médico, hospitalizações e do uso de medicamentos, como também, menor absenteísmo dos pais ao trabalho, uma vez que as crianças que recebem leite materno adoecem menos (GIUGLIANI, 2000).

O programa nacional de incentivo ao aleitamento materno, coordenado pelo Ministério da Saúde, teve início no começo dos anos 80 , com ênfase na informação aos profissionais de saúde e ao público em geral, adoções de leis para proteção da mulher no trabalho no período de amamentação e o combate à livre propaganda de leites artificiais para bebês.

Anterior a esta década, por algum tempo a prática do aleitamento materno deixou de ser priorizada, como resultado de vários acontecimentos sociais e interesses econômicos. Então, na década de 90, resgatou-se esta prática, no intuito de promover uma melhoria da qualidade de vida em todo o mundo, principalmente nos países em desenvolvimento.

Várias foram as medidas ministeriais para incentivar a prática de aleitamento materno. Uma delas foi a implementação da Iniciativa Hospital Amigo da Criança (IHAC) nas unidades de saúde, desenvolvida no Brasil em março de 1992, com apoio da UNICEF, da OMS e da Organização Panamericana da Saúde (OPAS). Esta iniciativa representa um esforço a mais para a promoção, incentivo e apoio ao aleitamento materno.

A Sociedade Civil Bem-estar Familiar no Brasil, 1997 (BEMFAM, apud GIUGLIANI, 2000), afirma que apesar do aumento das taxas de aleitamento materno, dos vários benefícios já comprovados e das várias ações ministeriais desenvolvidas, a tendência ao desmame precoce continua e o número de crianças amamentadas segundo a OMS ainda é pequeno. No Brasil a duração média do aleitamento materno é de sete meses, sendo de apenas um mês o exclusivo.

Com a implantação do programa nacional de incentivo ao aleitamento materno, iniciou-se um processo de conscientização dos profissionais enfatizando a responsabilidade de todos na promoção, incentivo e apoio ao aleitamento materno.

Como o enfermeiro é o profissional que mais estreitamente se relaciona com a mulher durante o ciclo gravídico-puerperal e tem importante papel nos programas de educação em saúde, durante o prénatal, ele deve preparar a gestante para o aleitamento, para que no pós-parto o processo de adaptação da puérpera ao aleitamento seja facilitado e tranquilo, evitando assim, dúvidas, dificuldades e possíveis complicações (BRASIL, 2002).

No período puerperal que o processo de lactação se torna concreto e a capacidade de amamentar da puérpera se torna alvo de críticas desencorajadoras e diante de dificuldades com o bebê é colocada a dúvida da quantidade e qualidade do leite materno. A mãe pode entender esta atitude como incapacidade de cuidar de seu filho e como conseqüência disso poderá inibir a lactação, devido à sua ansiedade. Profissionais enfermeiros capacitados devem estar ao lado da mãe, orientando-a no início do aleitamento materno e ajudando-a na busca de soluções para suas dúvidas quanto ao aleitamento materno (UNICEF; IBFAN, 2002).

O enfermeiro deverá estar próximo durante e após o parto, auxiliando as mães nas primeiras mamadas do recém-nascido, para que o aleitamento materno seja iniciado o mais precoce possível, de preferência imediatamente após o parto, conforme preconiza a World Health Organization (GIUGLIANI, 2000). Ele deve estar disponível, observando como está sendo a pega do recém-nascido, e respondendo perguntas quanto ao aleitamento materno e aos cuidados com o recém-nascido.

É necessária uma comunicação simples e objetiva durante a orientação, o incentivo e o apoio ao aleitamento materno, demonstrando diversas posições, promovendo relaxamento e posicionamento confortável, explicando a fonte dos reflexos da criança e mostrando como isso pode ser usado para ajudar na sucção do recém-nascido (ALMEIDA \& DO VALE, 2003).

O aleitamento materno sob livre demanda deve ser encorajado a fim de diminuir a perda de peso inicial do recém-nascido e promover o estímulo precoce da apojadura. Ele garante a manutenção do vínculo mãe e filho que se inicia na gestação, cresce e se fortifica, devendo portanto ser incentivado a sua continuidade para garantir bem-estar, segurança e saúde da criança (BRASIL, 2001).

Os primeiros dias após o parto são cruciais para o aleitamento materno bem sucedido, pois é nesse período que a lactação se estabelece, além de ser um período de intenso aprendizado para a mãe e 
adaptação do recém-nascido. Daí a importância do acompanhamento intensivo no pós-parto e através de visitas domiciliares após a alta hospitalar, pois várias dúvidas e problemas podem surgir e tornar a mulher vulnerável e insegura. Nesta etapa de adaptação às modificações puerperais, a mulher necessita conhecer sobre o auto-cuidado, o aleitamento, o planejamento familiar e os cuidados com o recém_nascido. Nesse período o enfermeiro poderá intervir reforçando as orientações, buscando solucionar os problemas, prevenindo e ajudando a superar as dificuldades da puérpera, evitando, assim, o uso de complementos e seus possíveis efeitos deletérios.

Para assegurar que todas as expectativas maternas e necessidades do recém-nascido quanto ao aleitamento sejam atendidas, é necessário que toda a equipe multiprofissional da instituição atue junto às puérperas e aos familiares, informando as estratégias e vantagens de se iniciar e dar continuidade ao processo de aleitamento.

GIUGLIANI (2000) afirma que os profissionais de saúde desempenham um papel muito importante na assistência à puérpera, assim, devem instrumentalizarse com conhecimentos técnico-científicos atualizados. Por vez, estarão colaborando com a garantia do direito de toda criança de ser amamentada, conforme o Estatuto da Criança e do Adolescente.

Como as atividades de prevenção e promoção para a saúde fazem parte do papel do enfermeiro, ele deve investir em atividades como visitas domiciliares, palestras, grupos de apoio e aconselhamento para incentivo e manutenção do aleitamento exclusivo, a fim de intensificar as ações promovidas durante o período de pós-parto hospitalar, como também, para garantir que o aleitamento materno continue após o fim da licença-maternidade. Quando a nutriz retorna à rotina de trabalho, ela necessita saber como fazer a retirada do leite para conservar a sua produção, como estocar e a forma de adiministrá-lo à criança, para evitar o desmame precoce.

É importante evidenciar como o enfermeiro está atuando nesta prática, pois buscando compreender a realidade é que novas ações poderão ser implementadas, e os futuros profissionais enfermeiros poderão se posicionar de forma objetiva, efetiva e completa, evitando lacunas na assistência e com isso aumentar a adesão da puérpera ao aleitamento e reverter os índices de desmame precoce.

As lacunas na assistência, geralmente decorrentes da ocupação do enfermeiro em atividades administrativas ou por falta de seu número adequado, pode resultar em pequena e/ou pouco expressiva atuação ou até falta de atuação do enfermeiro na assistência ao aleitamento materno no pós-parto. Esse fato é preocupante, pois facilita a ocupação desse campo por novas profissões e, como conseqüência, aumentado o risco de perda desse campo de atuação pelo enfermeiro.

Para que o enfermeiro coordene as suas tarefas, desde a administração até as atividades assistenciais, é necessário que ele sistematize a sua assistência para facilitar a solução de problemas e agilizar e dinaminazar suas ações.. Nessa perspectiva o enfermeiro conseguirá organização e sequência em suas atividades, evitando lacunas na assistência.

Mesmo que os profissionais de saúde busquem desempenhar ações específicas dentro de sua formação acadêmica durante a assistência de promoção, incentivo e apoio ao aleitamento materno, políticas institucionais devem garantir o exercício profissional de todos e apoiar a diversificação de suas atuações em benefício da mulher e da criança.

Estudar a atuação do enfermeiro na assistência ao aleitamento materno durante a hospitalização da puérpera é uma forma de evidenciar o seu papel e a importância de sua atuação, assim como da sistematização da assistência de enfermagem .

\section{OBJETIVOS}

\section{Geral:}

- Identificar a atuação do enfermeiro na assistência ao aleitamento materno durante a hospitalização da puérpera.

\section{Específicos:}

- Verificar o quantitativo de enfermeiros e as condições estruturais das maternidades para a atuação do enfermeiro na assistência ao aleitamento materno;

- Identificar quais os profissionais que compõem o grupo de promoção, incentivo e apoio ao aleitamento materno durante a assistência ao aleitamento materno

- Identificar como o enfermeiro sistematiza a assistência ao aleitamento materno.

\section{METODOLOGIA}

Trata-se de uma pesquisa de campo, descritiva, com abordagem quanti-qualitativa, realizada em três Instituições Públicas de Goiânia.

Como critérios de inclusão foi estabelecido: 1 . Para as instituições a serem pesquisadas: três maternidades públicas, sendo a primeira de administração a nível federal, a segunda estadual com o título de "Hospital Amigo da Criança" e a terceira municipal com os títulos de "Hospital Amigo da Criança" e "Maternidade Segura"; 2. Para os sujeitos a serem pesquisados: enfermeiros das maternidades.

Foram entrevistadas 21 enfermeiras envolvidas na assistência ao aleitamento materno no pós-parto hospitalar nos períodos de setembro a outubro de 2003. A amostra constitui-se de 6 enfermeiras de uma Maternidade Federal, 5 enfermeiras de uma Maternidade Estadual e 10 enfermeiras de uma Maternidade Municipal, .

O instrumento de coleta de dados constituiu-se de um roteiro de entrevista semi-estruturada, com abordagem na caracterização profissional, no conhecimento específico em aleitamento materno, na equipe de assistência, na estrutura física da unidade e na sistematização da assistência pelos enfermeiros. Este foi submetido à validação de conteúdo quanto a pertinência, a clareza, a abrangência, a organização lógica e a tendenciosidade dos itens (POLIT \& 
HUNGLER, 1995) por professores pesquisadores de áreas afins.

O projeto de pesquisa foi submetido à apreciação e aprovado pelas direções clínicas das Maternidades e pelo Comitê de Ética em Pesquisa Médica Humana e Animal do Hospital das Clínicas da Universidade Federal de Goiás, protocolo 062/2003 atendendo a resolução 196/96 do Conselho Nacional de Saúde (BRASIL, 1998).

O teste piloto foi realizado para testar a aplicabilidade do instrumento de coleta de dados e o procedimento metodológico da pesquisa.

O procedimento metodológico consistiu em abordar as enfermeiras por meio de entrevista gravada ou por escrito, conforme consentimento das mesmas, sobre a sua atuação na assistência ao aleitamento materno durante a hospitalização da puérpera.

Para a análise dos dados foram utilizados procedimentos de estatística descritiva, apresentados em forma de tabelas e gráficos com freqüência e percentual, e análise qualitativa das falas com categorização das mesmas para compreensão os significados ( LUDKE E ANDRÉ, 1986).

\section{RESULTADOS E DISCUSSÃO}

Toda a amostra foi constituída por profissionais enfermeiros do sexo feminino (100\%), 46,6\% casadas e entre a faixa etária de 27 e 57 anos, tendo a maioria $(61,8 \%)$ entre 25 e 38 anos.

Em relação à instituição de graduação, treze enfermeiras $(61,9 \%)$, concluíram sua graduação na Universidade Católica de Goiás (UCG) e as outras oito $(38,1 \%)$ na Universidade Federal de Goiás (UFG).

Entre as 21 enfermeiras, seis $(28,5 \%)$ pertencem ao quadro de enfermeiros de uma Maternidade Federal, cinco $(23,8 \%)$ de uma Maternidade Estadual e dez $(46,6 \%)$ de uma Maternidade Municipal.

Em relação ao tempo de atuação na instituição, das seis enfermeiras da Maternidade Federal, quatro $(19 \%)$ atuavam nesta instituição entre dez a quinze anos e duas $(9,5 \%)$ entre cinco a dez anos (Figura 1$)$. Em relação à titulação, quatro enfermeiras (19\%) eram especialistas (Administração Hospitalar, Terapia Intensiva, Saúde Pública e Obstetrícia), uma $(4,7 \%)$ cursava Especialização em Auditoria e uma (4,7\%) não cursara nenhuma especialização (Figura 2).

Figura 1. Tempo de atuação das enfermeiras nas instituições pesquisadas. Goiânia (GO), 2003.

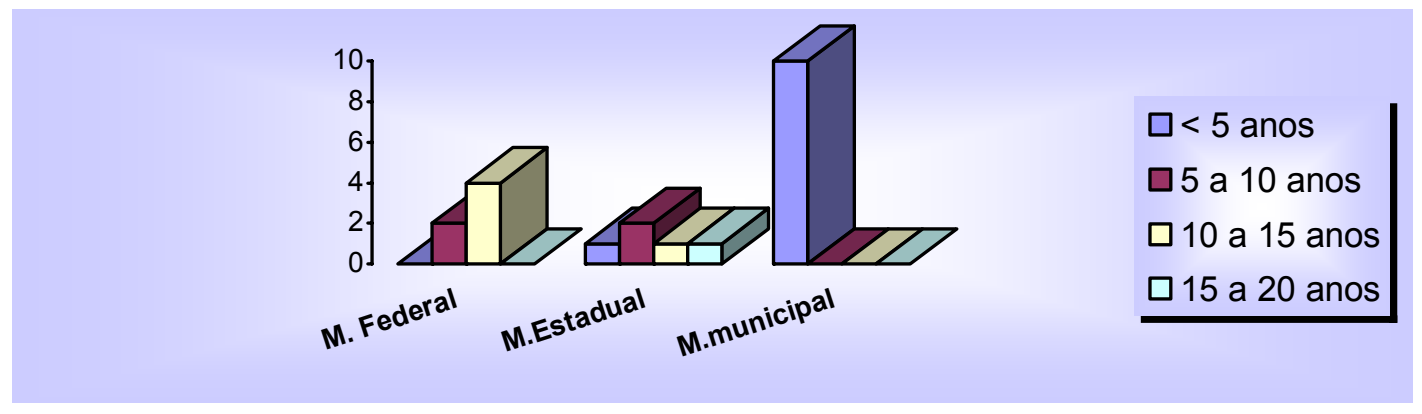

Na Maternidade Estadual, das cinco enfermeiras entrevistadas, duas $(9,5 \%)$ atuavam nesta instituição entre cinco a dez anos, uma $(4,7 \%)$ entre quinze a vinte anos, uma $(4,7 \%)$ entre dez a quinze anos e uma $(4,7 \%)$ atuava há menos de cinco anos (gráfico 1). Entre elas, duas $(9,5 \%)$ enfermeiras tinham título de especialista (Enfermagem Médico-cirúrgica e Obstetrícia), duas $(9,5 \%)$ estavam cursando a especialização no momento (Obstetrícia), e uma
$(4,7 \%)$ não possuia nenhuma especialização (gráfico 2).

As dez enfermeiras da Maternidade Municipal atuavam há menos de cinco anos na instituição (gráfico 1), sendo que destas, quatro (19\%) tinham título de especialista (Administração Hospitalar, Saúde Pública, UTI e Obstetrícia), quatro (19\%) estavam cursando especialização em Obstetrícia no momento e três $(14,2 \%)$ não tinham nenhuma especialização (gráfico 2).

Figura 2. Grau de titulação das enfermeiras nas instituições pesquisadas. Goiânia (GO), 2003.

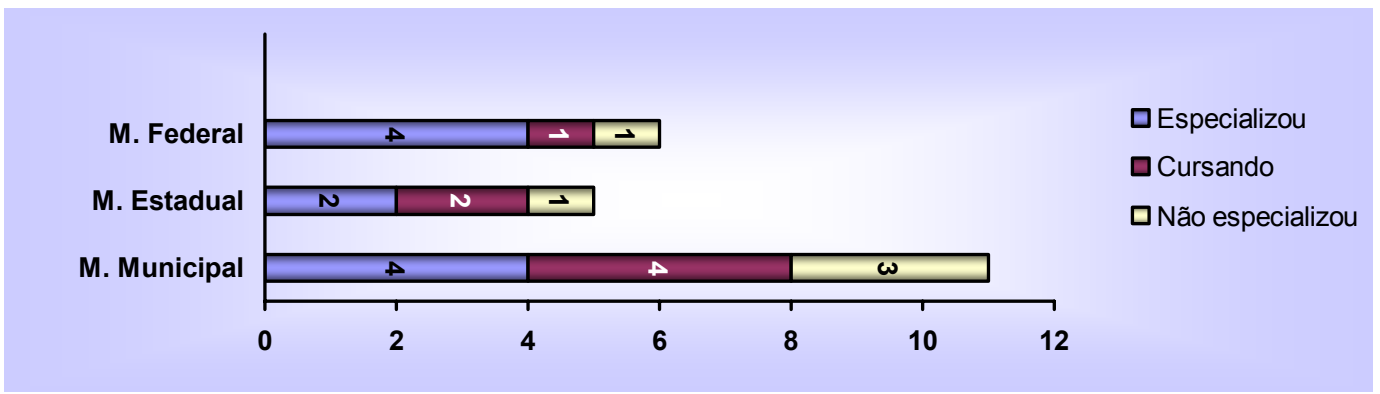




\section{CONHECIMENTO ESPECÍFICO EM ALEITAMENTO}

Os dados apresentados na tabela 1 , apontam que a maioria dos profissionais $(66,6 \%)$, adquiriram conhecimento sobre o aleitamento materno na graduação, porém treze $(61,9 \%)$ profissionais, relatam não ter sido suficiente, havendo uma grande distância entre a teoria e a prática.

Segundo GIUGLIANI (1994), o conhecimento é importante na atuação dos profissionais de saúde na promoção, incentivo e apoio ao aleitamento materno. A falta de conhecimento pode, na realidade, ser um obstáculo ao aleitamento materno, quando transmitidas informações incorretas e com falta de consistência às nutrizes.

Verifica-se que é necessário dar um enfoque maior ao aleitamento materno durante o ensino da assistência à mulher, enfatizando as novas teorias e sua aplicação prática. Assim como os profissionais devem buscar se atualizar através de cursos de capacitação e leituras de artigos e outras fontes sobre o assunto.

Quando abordadas a respeito de suas concepções sobre o aleitamento materno (AM), aleitamento materno exclusivo (AME) e período preconizado pelo Ministério da Saúde (MS) para o AME, dezessete $(80,9 \%)$ das enfermeiras entrevistadas, foram unânimes em responder que AM é primordial para a saúde do recém-nascido e traz vários benefícios tanto à nutriz quanto ao recémnascido e quatro (19\%) não manifestaram opinião alguma. Quanto ao AME, vinte (95,2\%) entrevistadas mencionaram que é a oferta do "leite do peito", sem nenhum outro complemento, água, chá ou outro tipo de leite nos primeiros seis meses de vida da criança e uma $(4,7 \%)$ das entrevistadas não manifestou opinião .

Os dados apresentados mostram que mais de $80 \%$ das entrevistadas conhecem o que a OMS e o MS preconizam: o aleitamento materno deve ser exclusivo, ou seja, somente leite humano materno deve ser oferecido ao recém-nascido, sem outros líquidos ou sólidos até os seis meses de idade.

$\mathrm{Na}$ concepção de FADUL \& XAVIER (1983) desde o início da vida do ser humano, um dos fatores de primordial importância é o acesso a uma nutrição básica, que pode ser obtida de forma eficiente por meio da prática do aleitamento materno. LAMOUNIER (1996) destaca que o aleitamento materno é uma prática natural, saudável e de menor custo.

Todas as instituições pesquisadas oferecem capacitação, sendo que a periodicidade varia de semestral a anual, destinando-se a toda a equipe multiprofissional. Nas instituições intituladas Amigo da Criança (maternidade estadual e municipal) o treinamento abrange também profissionais das áreas administrativa e de serviços gerais.

Quanto à participação nos cursos de capacitação, dezoito $(85,7 \%)$ enfermeiras tiveram participação e três $(14,2 \%)$ não. Aquelas que participaram, consideram que o curso foi suficiente no momento, porém, deveriam ser com maior periodicidade.

Tabela 1: Respostas das enfermeiras sobre a aquisição de: conhecimento teórico-prático sobre aleitamento materno na graduação e o seu grau de suficiência. Goiânia (GO), 2003.

\begin{tabular}{cccc}
\hline Variáveis & Respostas & $f^{\text {a }}$ & $\%$ \\
\hline Conhecimento & Sim & 14 & 66,6 \\
Teórico-prático & Não & 5 & 23,8 \\
& Não lembra & 2 & 9,5 \\
\hline Grau de suficiência & Não suficiente & 13 & 61,9 \\
& Suficiente & 1 & 4,7 \\
\hline
\end{tabular}

A capacitação dos profissionais envolvidos na promoção, no incentivo e no apoio ao aleitamento materno, é fundamental, pois a atualização contínua é um caminho para a promoção de assistência de qualidade e segurança à nutriz, a fim de melhorar a prática do aleitamento materno e incentivar a atuação intensiva dos profissionais para reduzir os índices de desmame precoce,.

O profissional de saúde, portanto, deve ter a humildade de reconhecer que precisa estar sempre aprendendo mais sobre aleitamento materno e atualizar-se periodicamente (GIUGLIANI, 1994).

Além da capacitação, o profissional deve ter o compromisso de aplicar na assistência os conteúdos adquiridos para garantir à mulher e à criança o seu direito de assistência humanizada e de qualidade.

\section{Equipe de assistência ao aleitamento materno exclusivo}

Nas três maternidades pesquisadas, tem-se uma equipe multiprofissional de assistência ao aleitamento materno exclusivo composta por enfermeiros, técnicos e auxiliares de enfermagem, médicos (obstetras e pediatras), sendo que na maternidade estadual e municipal esta equipe também é composta por fonoaudiólogos, psicólogos e assistente social.

A Maternidade Municipal também conta com o serviço de banco de leite, que garante assistência tanto ao recém-nascido nascido na instituição, quanto aos às da comunidade. Nesta unidade atuam o Bioquímico e o Nutricionista, intervindo em situações diferenciadas e específicas.

No banco de leite humano é realizada a coleta de leite materno humano para atender aos casos 
especiais. Com isso, ele faz a diferença ao beneficiar as puérperas que não podem amamentar aos recém nascidos prematuros, de baixo peso, imunologicamente deficiente ou com alterações gástricas e processos alérgicos, contando com a mãode-obra de uma equipe multiprofissional cuja atuação está voltada exclusivamente ao aleitamento materno.

As atividades desempenhadas pela equipe multiprofissional de informar, apoiar, aconselhar e orientar a puérpera durante o aleitamento materno tem como objetivo comum a adesão da mãe ao aleitamento materno e à nutrição adequada do recémnascido. Embora, as atividades desempenhadas pelos profissionais dependam da área de atuação de cada um.

Segundo CORREAA \& JULIANI (2002), o papel de informação é de responsabilidade de todos os profissionais de saúde, além disso, estes devem assumir um papel de apoio. Porém, é necessário ter conhecimento e dominar o assunto.

No gráfico 3, estão apresentadas as opiniões das entrevistadas quanto a adequação da equipe de assistência ao aleitamento materno de sua unidade. Onze $(52,3 \%)$ enfermeiras afirmaram que a equipe atende às necessidades da instituição, tanto no que se refere ao número de profissionais quanto às categorias interdisciplinares envolvidas. Duas $(9,7 \%)$ não apresentaram opinião. Oito $(38,0 \%)$ entrevistadas acreditam ser inadequada devido ao número pequeno de profissionais envolvidos na equipe, à falta de educação continuada e à falta de integração da equipe, comprovados nos seguintes relatos:

"Não, porque falta profissional, falta mais
gente."
"Não é cem por cento ainda não, a gente está
com uma falta de auxiliar e técnico de
enfermagem.(...) Então falta recursos
humanos, alguns profissionais específicos
também têm que ser remanejados, por não se
adequarem."
"Não. Falta integração e disposição para
desenvolver o trabalho".

Das onze $(52,3 \%)$ entrevistadas que afirmaram ser adequada a equipe responsável pelo aleitamento materno, uma $(4,7 \%)$ atua na Maternidade Federal, cinco $(23,7 \%)$ na Maternidade Estadual e cinco $(23,7 \%)$ atuam na Maternidade Municipal.

Das oito $(38 \%)$ entrevistadas que referiram ser inadequada a sua equipe, cinco $(23,8 \%)$ atuam na Maternidade Federal e três $(14,2 \%)$ atuam na Maternidade Municipal. As duas (9,5\%) entrevistadas que não apresentaram opinião atuam na Maternidade Municipal

Figura 3. Opiniões das entrevistadas sobre a adequação da equipe de assistência ao aleitamento materno de sua unidade. Goiânia (GO), 2003.

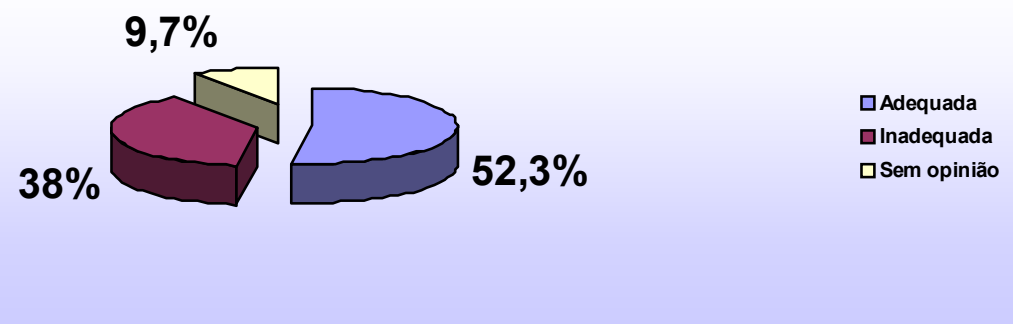

Pode-se perceber que na Maternidade Federal, onde não há o título de amigo da criança, o percentual de entrevistadas que referiram ser inadequada a equipe de assistência ao aleitamento materno e a falta de um treinamento contínuo e estendido a todos os profissionais é maior. Nas outras duas instituições que têm o título de hospital amigo da criança, todos os profissionais da equipe de saúde, que prestam assistência em aleitamento materno, fazem cursos de capacitação continuamente para implementar a assistência adequada.

A equipe de enfermeiros das três Maternidades que atuam na assistência direta à puérpera com promoção, incentivo e apoio ao aleitamento materno está descrita na tabela 2.

A maternidade Federal é composta por oito profissionais. Todos realizam assistência à puérpera. Destas, seis $(75 \%)$ participaram da pesquisa. Elas referiram que esse quantitativo de enfermeiros é insuficiente para se prestar uma assistência de qualidade, como também, destacaram ser insuficiente e inadequada a estrutura física (equipamentos e materiais) ao atendimento, comprometendo ainda mais a assistência, como pode se comprovar nos depoimentos a seguir:

"Não, por falta do banco de leite."

“... eu acho assim, as enfermarias são pequenas, deveria ter uma cadeira de descanso em cada leito. Não tem. Ficam sentadas na cama, e que muitas vezes não consegue fazer o leito levantar".

No que se refere a ações que a instituição tem desenvolvido a fim de viabilizar a participação do enfermeiro, uma $(16,7 \%)$ das entrevistadas mencionou a realização de apenas um treinamento e seminário. $E$ as outras cinco $(83,3 \%)$ entrevistadas, referiram que a instituição nada faz para viabilizar a participação do 
enfermeiro na assistência e promoção ao aleitamento materno, como se destaca nos seguintes depoimentos:

"Não tem oferecido cursos."

"Não tem feito nada. Porque só tem um enfermeiro para vinte e quatro leitos. $A$ necessidade aqui seria de mais enfermeiros. Poderia ter um enfermeiro só para isso, pra ele passar de leito em leito e orientar a mãe, todo dia, todas as mães."

$\mathrm{Na}$ Maternidade Estadual, são sete os enfermeiros que prestam assistência à puérpera. Destas, cinco participaram da pesquisa. Uma (20\%) entrevistada referiu que o número de enfermeiros que atuam na assistência ao aleitamento materno é insuficiente, as outras quatro $(80 \%)$ referiram ser suficiente. Três $(60 \%)$ disseram ser adequada a estrutura física (materiais e equipamentos) da unidade como observa-se nos relatos:

"Pra você incentivar, proteger, promover o aleitamento materno, na realidade você não precisa de material, você precisa de pessoal e de vontade própria também..."

Quanto as ações programadas pela instituição para viabilizar a participação do enfermeiro, três (60\%) das entrevistadas referiram que a instituição realiza educação continuada e palestras e duas (40\%) referiram que a instituição nada faz para permitir a atuação efetiva do enfermeiro na assistência ao aleitamento materno e garante e incentiva a atuação exclusiva do fonoaudiólogo na promoção, incentivo e apoio ao aleleitamento materno.

Na Maternidade Municipal são doze o número de enfermeiros que assistem à puérpera. Destas, dez foram entrevistadas. Cinco (50\%) referiram ser insuficiente o número de enfermeiros. Nove (90\%) referiram que a estrutura física é adequada. Uma $(10 \%)$ entrevistada não manifestou opinião.

Das dez entrevistadas, oito (80\%) referiram que a unidade desenvolve várias ações que viabilizam a atuação do enfermeiro, promovendo cursos, treinamentos. $O$ incentivo às ações do enfermeiro e investimento na atualização do mesmo pode ser apreendido na seguinte fala:

"A instituição é envolvida com a enfermagem, várias enfermeiras estão fazendo pósgraduação, incentivadas pela diretoria."

Uma (10\%) referiu que a instituição nada faz e uma $(10 \%)$ não fez referência.

Somente na Maternidade Federal constata-se uma carência de ações promovidas pela instituição, estrutura física inadequada e número insuficiente de enfermeiros que assistem o aleitamento materno no puerpério imediato. Os enfermeiros atuam somente na assistência aos agravos de saúde da puérpera, delegando a técnicos e auxiliares de enfermagem o papel de orientação e supervisão do aleitamento materno.

Tabela 2. Relação de enfermeiros da equipe de assistência à puérpera, estrutura física e ações desenvolvidas pela instituição para promoção do aleitamento materno, segundo depoimentos das entrevistadas. Goiânia (GO), 2003.

\begin{tabular}{|c|c|c|c|c|c|c|c|c|c|c|c|c|}
\hline \multirow{3}{*}{$\begin{array}{l}\text { Instituição/ } \\
\text { relatos }\end{array}$} & \multicolumn{4}{|c|}{$\begin{array}{l}\mathrm{N}^{\circ} \text { de enfermeiros que } \\
\text { assistem a puérpera }\end{array}$} & \multicolumn{4}{|c|}{$\begin{array}{l}\text { Ações que viabilizam a } \\
\text { participacão do enfermeiro }\end{array}$} & \multicolumn{4}{|c|}{ Estrutura física } \\
\hline & \multicolumn{2}{|c|}{ Adequado } & \multicolumn{2}{|c|}{ inadequado } & \multicolumn{2}{|c|}{ Presentes } & \multicolumn{2}{|c|}{ Ausentes } & \multicolumn{2}{|c|}{ Adequada } & \multicolumn{2}{|c|}{ inadequada } \\
\hline & $\mathrm{F}$ & $\%$ & $\mathrm{~F}$ & $\%$ & $\mathrm{~F}$ & $\%$ & $\mathrm{~F}$ & $\%$ & $\mathrm{~F}$ & $\%$ & $\mathrm{~F}$ & $\%$ \\
\hline M. Federal & 0 & 0 & 6 & 100 & 1 & 16,7 & 5 & 83,3 & 0 & 0 & 6 & 100 \\
\hline M. Estadual & 4 & 80 & 1 & 20 & 3 & 60 & 2 & 40 & 3 & 60 & 2 & 40 \\
\hline M. Municipal & 5 & 50 & 5 & 50 & 8 & 80 & 1 & 10 & 9 & 90 & 0 & 0 \\
\hline
\end{tabular}

Na Maternidade Estadual, a maioria dos relatos referentes à estrutura física e ações desenvolvidas pela instituição para viabilizar a participação do enfermeiro, foram positivas.

Apesar da maioria das entrevistadas da Maternidade Estadual referir que o número de enfermeiros é adequado, para desenvolver suas ações gerais, observou-se nos relatos, que a promoção do aleitamento materno que deveria estar integrada às ações do enfermeiro, está sendo realizada exclusivamente pelo fonoaudiológo. $\mathrm{O}$ enfermeiro prioriza suas ações, no puerpério imediato, para a assistência curativa e administração da unidade, como observa-se nos relatos:

"O fonoaudiólogo aqui só lida com o aleitamento materno... ele planeja e avalia as ações."

"Quem tá diretamente na assistência é a fono... a prática mesmo desempenhada pelo enfermeiro é quando tem alguma complicação..." 
Na Maternidade Municipal a maioria dos relatos foi favorável no que diz respeito à estrutura física e ações desenvolvidas pelas referida instituição para viabilizar a participação do enfermeiro na assistência ao aleitamento materno e quanto à adequação do número de enfermeiros houve um equilíbrio de opiniões.

Segundo CECCATO \& VAN DER SAND (2001), - cuidado necessita ser a filosofia da instituição, permitindo as condições indispensáveis para desenvolvê-lo. Essas condições são recursos humanos qualificados, materiais e tecnologia, bem como a apropriada estrutura física.

GIUGLIANI (2000) refere que no contexto do processo de cuidar, o enfermeiro encontra no aleitamento materno situações que devem ser diagnosticadas, cujas intervenções estão no âmbito de resolução da enfermagem, isto é, são ações independentes.

Portanto, o enfermeiro deve estar consciente e disponível para atuar diretamente com as puérperas, observando a primeira mamada e a pega, prevenindo futuras complicações. Pois o enfermeiro é o profissional que comprovadamente está mais habilitado e capacitado para desfazer os mitos e tratar as complicações. prevenção é uma das filosofias básicas da enfermagem. $O$ enfermeiro deveria assumir o seu papel de educador, orientador e incentivador das práticas corretas de aleitamento materno e, também, garantir a assistência multidisciplinar à mulher e à criança.

Como o enfermeiro permanece 24 horas na unidade, assiste diretamente ao binômio mãe e filho. É seu papel atuar na promoção do aleitamento materno, na prevenção de complicações, assim como, no tratamento destas. A sua assistência é decisiva para o início, manutenção e sucesso do aleitamento materno.

A Maternidade Municipal se mostrou diferente das demais, pelo incentivo ao aleitamento materno prioritariamente do enfermeiro, pois nesta instituição, a atuação do enfermeiro contempla ações preventivas (orientações individuais e coletivas, oficinas de educação continuada, acompanhamento da primeira mamada, pega e posições corretas, ordenha) e curativas, no diagnóstico precoce de problemas (mastite, ingurgitamento), como se observa nos relatos a seguir:

\section{"As atividades desenvolvidas pelo enfermeiro são: estímulo e supervisão para a amamentação e alta somente após amamentação satisfatória." \\ "Como enfermeiro dentro de uma filosofia comum, fazemos orientações sobre AME, seus mitos e tabus, ensinamos como amamentar, supervisionamos amamentação, estimulamos a amamentação e as pacientes são liberadas somente pela enfermagem quando estão amamentando bem."}

Com isso o enfermeiro tem a possibilidade de oferecer uma assistência de qualidade, assumindo seu papel de orientador, educador e conselheiro, sobressaindo na equipe de assistência já que está em contato constante e direto com o binômio mãe e filho.

Conforme os dados apresentados, pode-se perceber diferenças entre as instituições. Primeiramente, determinadas pela política de saúde, assim como, pela filosofia de cada unidade. Uma possui título de Hospital Amigo da Criança e Maternidade Segura, outra somente título de Hospital Amigo da Criança e a outra nenhum título. Certamente os benefícios à mulher e à criança são diferenciados.

O MS junto à UNICEF quando idealizou estes títulos, objetivando a qualidade da assistência à mulher e à criança, preconizou várias ações que devem ser rigorosamente seguidas para se obter e manter os títulos, assim como, os recursos para incentivo.

A instituição interessada necessita realmente mudar sua filosofia de assistência ao cliente a fim de atender a essa prática de saúde vigente. Para tanto, necessita haver um envolvimento de toda a unidade como também garantir a capacitação de recursos humanos e a assistência multidisciplinar.

Observa-se, pelos dados apresentados, que a instituição que possui mais títulos é a mais envolvida e compromissada com a qualidade do seu quadro de enfermeiros, como com a adequação da estrutura física e consequentemente com a qualidade da assistência à mulher e à criança.

\section{Sistematização da assistência do enfermeiro}

"No contexto da enfermagem, 'sistematizar' pode significar o uso de métodos para planejar a assistência de enfermagem preventiva, curativa e reabilitadora, visando ao atendimento das necessidades básicas do indivíduo" (DANIEL ,1981, p.4).

O plano terapêutico de enfermagem inclui: o histórico de enfermagem, análise dos dados colhidos e identificação de problemas (Diagnóstico de Enfermagem, Planejamento, Implementação dos Cuidados , Avaliação e Registro).

Ao analisar os relatos das 21 (100\%) enfermeiras entrevistadas a cerca da sistematização da assistência, apresentada no gráfico 4 , constatamos que apenas nove $(42,8 \%)$ realizam a coleta de dados, porém com algumas ressalvas:

\section{“...daquelas mães que tem mais dificuldades, só preencho os formulários".}

Doze $(57,1 \%)$ não realizam a coleta de dados/histórico de enfermagem, alegando ser elevado o número de pacientes internadas e que não existe um protocolo específico/padronizado na instituição para realização desta coleta.

Quanto ao Diagnóstico de Enfermagem, oito (38\%) referiram que formulam o Diagnóstico de Enfermagem, porém de forma intuitiva, sem basear em nenhuma teoria científica. Treze (61,9\%) entrevistadas referiram que não formulam Diagnósticos de Enfermagem. 
Dezesseis $(76,1 \%)$ entrevistadas referiram que planejam e implementam a assistência com base nos problemas apresentados a cada plantão e as outras cinco $(23,8 \%)$ referiram que não planejam e não implementam ações. Diante disto, observa-se que as entrevistadas não seguem as etapas operacionais da sistematização, portanto, não detectam todas as prioridades relacionadas àas necessidades humanas básicas afetadas e com isso, provavelmente, ocorrem lacunas na implementação da assistência.

Figura 4. Número de entrevistadas que realizam as etapas do processo de enfermagem. Goiânia (GO), 2003.

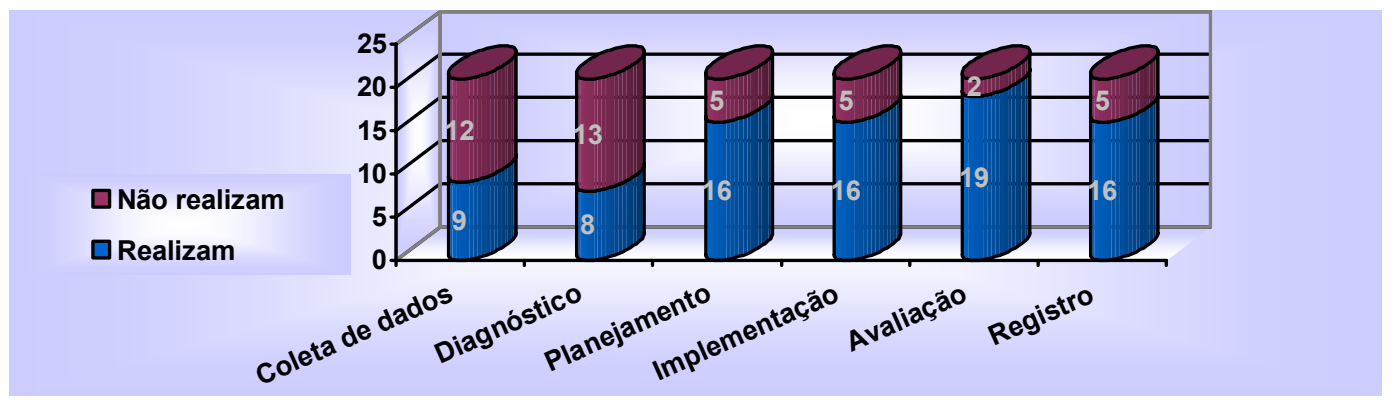

Dezenove (90,4\%) enfermeiras referiram que avaliam a assistência prestada ao verificar a melhora da cliente por meio de questionamentos, observação e checagem das evoluções diárias e duas $(9,5 \%)$ não avaliam sua assistência de nenhuma forma.

Ocorre um registro das atividades diárias no prontuário da cliente e/ou no livro de registros de enfermagem por parte de dezesseis $(76,1 \%)$ entrevistadas.

NAKATANI (2000) refere que seguir todas essas etapas operacionais garante um atendimento de qualidade durante o período em que o cliente estiver sob cuidados profissionais de tal categoria, evitando cuidados intuitivos e não embasados num conhecimento científico.

\section{CONCLUSÃO}

As maternidades pesquisadas tem governabilidade de níveis diferentes: federal, estadual e municipal. As maternidades estadual e municipal receberam o título de "Hospital Amigo da Criança" e a segunda mais o título de "Maternidade Segura". Ambas possuem equipe multiprofissional de promoção, incentivo e apoio ao aleitamento materno composta por Enfermeiros, Médicos, Psicólogos, Fonaudiólogos e Assistente Social com a participação de Nutricionista e de Bioquímico somente na maternidade municipal onde tem o Banco de Leite Humano.

Todas as enfermeiras têm atuação e conhecimento específico em aleitamento materno, mas nenhuma realiza a sistematização da assistência de enfermagem devido a demanda elevada de internações, déficit no quadro de enfermeiros e não implantação da metodologia de assistência na unidade. Somente a maternidade municipal apresenta estrutura física adequada, banco de leite humano e quantitativo de enfermeiros suficiente para a atuação eficaz e direcionada ao aleitamento materno.

$\mathrm{Na}$ maternidade estadual o fonaudiólogo tem atuação exclusiva e maior na promoção, no incentivo e apoio ao aleitamento materno do que o enfermeiro, principalmente pelo fato do quantitativo de enfermeiros ser insuficiente para a sua atuação eficaz e direcionada ao aleitamento materno.

A atuação do enfermeiro na promoção, no incentivo e no apoio ao aleitamento materno foi mais expressiva e efetiva na maternidade que apresenta filosofia, estrutura física e equipe multiprofissional de referência no parto humanizado e títulos de "Hospital Amigo da Criança" e "Maternidade Segura". Ela atende às novas diretrizes preconizadas pelo Ministério da Saúde para a Saúde da Mulher e da Criança, como também, apresenta uma atuação efetiva e expressiva do enfermeiro na equipe de aleitamento materno por garantir condições e valorização ao trabalho do enfermeiro no processo de educação em saúde e assistencial.

Concluiu-se diante das diferenciadas condições da três maternidades, referentes a equipe multiprofissional, o quadro de enfermeiros, à estrutura física e a ausência ou aplicação incompleta da sistematização da assistência de enfermagem, podese destacar que a atuação do enfermeiro na promoção, incentivo e apoio ao aleitamento materno, tem influência de todos esses fatores, mas prioritariamente da falta de sistematização da assistência de enfermagem.

A sistematização da assistência de enfermagem garante que as ações da equipe tenham visibilidade e especificidade. Ao realizar o processo de enfermagem as ações tornam-se efetivas e de maior qualidade facilitando adaptação da puérpera para o auto-cuidado, para os cuidados com o recémnascido e consequentemente maior adesão e sucesso no aleitamento materno, diminuindo as complicações no puerpério, e o tempo de internação e consequentemente gerando economia para os 
setores de assistência a saúde da mulher e da criança.

\section{REFERÊNCIAS BIBLIOGRÁFICAS}

ALMEIDA, J.S.; VALE, I.N.. Enfermagem Neonatal e aleitamento materno [online]. Disponível em:

http://www.aleitamento.org.br/arquivos/enfermeira.html . Acesso em 26 mar. 2003.

BRASIL. Ministério da saúde. Conselho Nacional de Saúde. Resolução n. ${ }^{\circ} 196$ de 10 de Outubro de 1996. Diretrizes e normas regulamentares da pesquisa envolvendo seres humanos. Cadernos de Ética em Pesquisa. N. ${ }^{\circ}$ 1.Julho. Brasília, 1998.

BRASIL. Ministério da Saúde. Como ajudar as mães a amamentar. Brasília, 2001.

CECCATO,S.R.; VAN DER SAND, I.C.P. O cuidado humano como princípio da assistência de enfermagem à parturiente e seus familiares. Revista Eletrônica de Enfermagem, v.3, n.1, 2001. Disponível: http://www.fen.ufg.br/revista/revista3 1/cuidado.html.

Acesso em 26 mar. 2003.

CORRÊA, C.R.H.; JULIANI, C.M.C. Aleitamento materno: Conhecimentos e atitudes da equipe de enfermagem. Revista Paulista de Enfermagem. v. 21, n.1, p.84-94, 2002.

DANIEL, L.F. A enfermagem planejada. São Paulo: EPU, 1981.

FADUL, F.D.; XAVIER, L.F. Fatores que contribuem para o desmame precoce. Revista Brasileira de Enfermagem. v.36, p. 213-220, 1983.

GIUGLIANI, E.R.J. O Aleitamento Materno na prática clínica. Jornal de pediatria. v. 76, Supl. 3, p. 238-252, 2000. Disponível: http://www.jped.com.br/conteudo/0076-s238/port.asp?cod=161. Acesso em: 26 mar. 2003]. GIUGLIANI, E.R.J. Amamentação: Como e porque promover. Jornal de pediatria, v.70, n.3, 138-47,1994. Disponível em: http://www.jped.com.br//conteudo/9470-03-138/port.asp?cod=769. Acesso em 26 mar 2003.

ICHISATO, SMT.; SHIMA, AKK. Aleitamento Materno e as Crenças Alimentares. Revista Latino-Americana de Enfermagem. v. 9, n. 5, p. 70-6, 2001.

ICHISATO, SMT.; SHIMA, AKK. Revisitando O desmame precoce através de recortes da história. Revista Latino-Americana de Enfermagem. v. 10, n.4, p.578-85, 2002.

LAMOUNIER, J.A.. Promoção e incentivo ao aleitamento materno: Iniciativa Hospital Amigo da Criança. Jornal de pediatria. v.72, n.6, p. 363-368, 1996.

http://www.jped.com.br//conteudo/96-72-06-

363/port.asp?cod=644. Acessp em 19 Abr. 2003.

NAKATANI, A.Y.K.. Processo de enfermagem: Uma proposta de ensino através da pedagogia da problematização. 2000. 230p. Tese (Doutorado)Escola de Enfermagem de Ribeirão Preto, Universidade de São Paulo, Ribeirão Preto.

POLIT, F. D.; HUNGLER, P. B.. Fundamentos de Pesquisa em Enfermagem. Porto Alegre: Artes Médicas, 1995.

UNICEF; IBFAN. Como o leite materno protege os recém-nascidos. Documento sobre $\mathrm{O}$ mês de amamentação.

Disponível: http://www.aleitamento.org.br/arquivos/arquivos.htm. Acesso em 24 Mar. 2003.

VENÂNCIO, S.I. Dificuldades para o Estabelecimento da Amamentação: O Papel das Práticas Assistenciais das Maternidades. Jornal Pediatria, 79 (1): p.1-2, 2003. Disponível

em: http://www.jped.com.br/conteudo/port resumo.asp?var Artigo=927. Acesso em 19 Abr. 2003.

LUDKE, M.; ANDRÉ M. E.D. A. Pesquisa em Educação: abordagens qualitativas. São Paulo: E.P.U; 1986.

Texto original recebido em 13/10/2004 Publicação aprovada em 10/12/2004 